\title{
Assessment of knowledge in healthcare workers about diabetes and complication attending structured workshop before ramadan.
}

\footnotetext{
1. MBBS, FCPS, MRCP (UK), FRCP (EDIN.),

FRCP (GLASGOW), FRCP

(LONDON), MCPS-HPE

Associate Professor Medicine

2. MBBS, Dip Card

Registrar Medicine

3. MBBS, FCPS

Senior Registrar Medicine

4. MBBS, FCPS

Senior Registrar Medicine

5. MBBS

House Officer Medicine

$1,2,3,4,5$

Ameer-ud-Din Medical College,

Lahore General Hospital, PGMI.

Correspondence Address:

Dr. Muhammad Imran Hassan Khan

Associate Professor Medical Unit-III

Ameer-ud-Din Medical College,

Lahore General Hospital, PGMI.

mimranhkhan@hotmail.com
}

Article received on:

29/05/2020

Accepted for publication:

$12 / 08 / 2020$
Muhammad Imran Hasan Khan', Salman Shakeel², Rana Asif Sagheer ${ }^{3}$, Hafiz Ehsan Ullah, Usama Azhar ${ }^{5}$

ABSTRACT... Objectives: International Diabetes Federation (IDF) has formulated Diabetes and Ramadan (DAR) guidelines, which provide guidance. Assess the knowledge of Healthcare workers before workshop, and to compare afterwards. Study Design: Experimental Study. Setting: Medical Unit-III, Diabetes Endocrine and Metobilc Center Lahore General Hospital, Lahore. Period: 2 years, 2019 and 2020. Material \& Methods: This study was carried out on the participants of workshop. A pretest was given to participants. Questions assessed the knowledge on Complications, Risk Stratification, Diet and Exercise, when to break their fast and adjustment in the dosage of different medications used by diabetics. A 90 minute interactive workshop was carried out. Participants were encouraged to question and get justifications for better understanding. Afterwards, a posttest was carried out. Data was assessed using SPSS, and a simple t-test was applied. Results: There was gross improvement in retention of knowledge in all areas. It was also statistically significant when t-test was applied. Conclusion: Interactive workshop pattern improves the retention of knowledge among participants. It was a better way to deliver knowledge, than conventional lecture.

Key words: $\quad$ Guidance, Knowledge, Ramadan, Retention.

Article Citation: Khan MIH, Shakeel S, Sagheer RA, Ullah HE, Azhar U. Assessment of knowledge in healthcare workers about diabetes and complication attending structured workshop before Ramadan. Professional Med J 2020; 27(11):2504-2510. https://doi.org/10.29309/TPMJ/2020.27.11.5018

\section{INTRODUCTION}

Ramadan comes every year, in which Muslims fast for a month according to lunar calendar. With more than 1.8 billion Muslims all over the world, it becomes all the more important to make it safe. ${ }^{1}$ Challenges faced by people vary according to climate. Reason being that the lunar calendar is shorter in duration, and hence can result in Ramadan rotating in different seasons in the same country. ${ }^{2}$

Safety of fasting becomes more important when we are talking about it in the presence of chronic diseases like Diabetes. Having diabetes, demands a change in life style during fast, with regular exercise and change in diet patterns and taking medicine at appropriate time. With long fasting hours in some parts of the world, counting over 20 hours in a day, it becomes very challenging. At the same time, it is important that the Healthcare workers should have appropriate knowledge to guide fasting diabetics. ${ }^{3}$ International Diabetes Federation (IDF) formulated Diabetes and Ramadan (DAR) guidelines, which were published first in 2017.4 They provided guidance on topics to be addressed. Main focus was on Risk stratification, Diet and Fluid balance, Exercise frequency with timing, Frequency of blood sugar monitoring, when to break your fast and how to adjust medication, especially those which can cause hypoglycemia.

Shah et al ${ }^{5}$ documented in a study through pretest and posttest, that the knowledge gained through practical approach of teaching on ultrasound was more useful in neurology students. They assessed improvement after using hands on use of ultrasound, through pretest and posttest. However, number of participants in this study were small. Our study in comparison, assessed the knowledge portion only, with a higher number of participants. 
Mohyuddin et al published a study, documenting the evaluation of high-fidelity simulation with interactive case discussion for managing Brady arrhythmias using mannequin. They concluded through pre and posttest that knowledge was equally retained with case discussion. Our study in comparison used only case discussion, with a variety of participants from different parts of the province. Also, our number of participants were more than 300, as compared to them which were 61. Main instructors in our study remained same.

Aim of this study was to assess the knowledge of Healthcare workers before workshop, and to compare it after workshop through pretest and posttest. In this way, we gauged improvement in retention of knowledge.

\section{MATERIAL \& METHODS}

It was Experimental, Pre-test and Post-test design, carried out on the record of participant responses of 2019 and 2020. Participants were invited with an electronic poster, and only those who were MBBS, or having any post-graduation were selected. There was no age limit to selection, but it was kept in mind that only those doctors should be selected who were involved in the management of Diabetic patients. It could be General practice or hospital based, public or private, with no discrimination. For a good interactive workshop, maximum of up to 60 participants were included in one workshop, and minimum up to 20 , so that a healthy group activity can be generated in all four groups. All non MBBS people wishing to participate were not included. Same was for doctors not involved in the diabetic patient care. At the start of workshop, an induction pack was distributed among all participants, which included reading material from IDF DAR guidelines, a pretest and a posttest response sheet, program copy, evaluation sheet to be filled at the end and all four scenarios. Participants were given certificates at the conclusion, and they were allowed to take home induction packs, for future reference.

This was the fourth consecutive year that Diabetes Endocrine and Metabolic Center (DEMC) carried out workshops in different cities of Punjab, Pakistan. This study was carried out on the data filled by participants of these workshops for the year 2019 and 2020.

A Medical Educationist was involved to prepare the workshop according to IDF DAR guidelines. Curriculum was devised, cases were made after discussion in each risk group, and participants were divided into four groups according to risk groups of Low, Moderate, High and Very High. Questions were included in each group to address all portions of guidelines.

Each group was encouraged to identify team leader, divide tasks in the scenario, and select a presenter from amongst them. Preparation time of 10 to 15 minutes was given to them, after which they were given 5 minutes to present their answers, and 5 minutes for general discussion and critique. After two scenarios, a concluding presentation was given for 10 to 15 minutes, addressing all correct replies. A pretest was given to all participants at start of workshop, which checked knowledge on Complications, Risk Stratification, Diet and Exercise, when to break their fast and adjustment in the dosage of different medications used by diabetics. At completion of Workshop, a posttest was carried out on same questions. A panel of experts in the field was also available to help out, along with the facilitators. Facilitators remained common in each workshop, and were available to help participants of each group, in executing this pattern. They did not helped out in answers, rather encouraged participants to find them on their own. Data collected through this way was assessed using SPSS, and a simple t-test was applied to check significance.

\section{RESULTS}

A total of 676 participant data was included from 13 workshops between 2019 and 2020, starting 8 weeks before Ramadan each year, and ending at the arrival of Ramadan. 316 responses were considered complete, and included in this study. 360 responses were considered incomplete, or not filled by the participants, and excluded.

Ten questions were put in front of everyone, which 
included knowledge about complications, factors falling into low risk category, high risk category, absolute indication to halt the fast, caloric requirement during Ramadan, Sulphonylurea dose adjustment, Metformin dose adjustment, DPP-4 dose adjustment, Short and long acting insulin dose adjustment and Pre mixed insulin dose adjustment.

It was assessed that patient response in the pretest was most poor for the knowledge of High risk factors used in risk stratification, which was $21.5 \%$. This was followed by knowledge on Sulphonylurea dose adjustment (39.2\%), Metformin dose adjustment (45.6\%) and then short and long acting Insulin dose adjustment $(48.1 \%)$. Best response in the knowledge was on the levels of blood sugar to break your fast
(82.3\%). Rest of the question responses were above $50 \%$, and less than $60 \%$ (Table-II, Figure-1 \& 2).

In the posttest response, there was significant change. All the responses were improved at more than $90 \%$, except for the Short and long acting insulin knowledge (89.9\%). Most significant improvement was in the DPP-4 dose adjustment (98.7\%). (Table-Il, Figure-1 \& 2)

Simple t-Test was applied for the results. A p value was calculated, between the responses of pretest and posttest. It was observed that $p$ value was less than 0.000 in all of them (Table-l). Hence proving that the workshop participants did improved and retained the knowledge given by this method, till the end of the workshop.

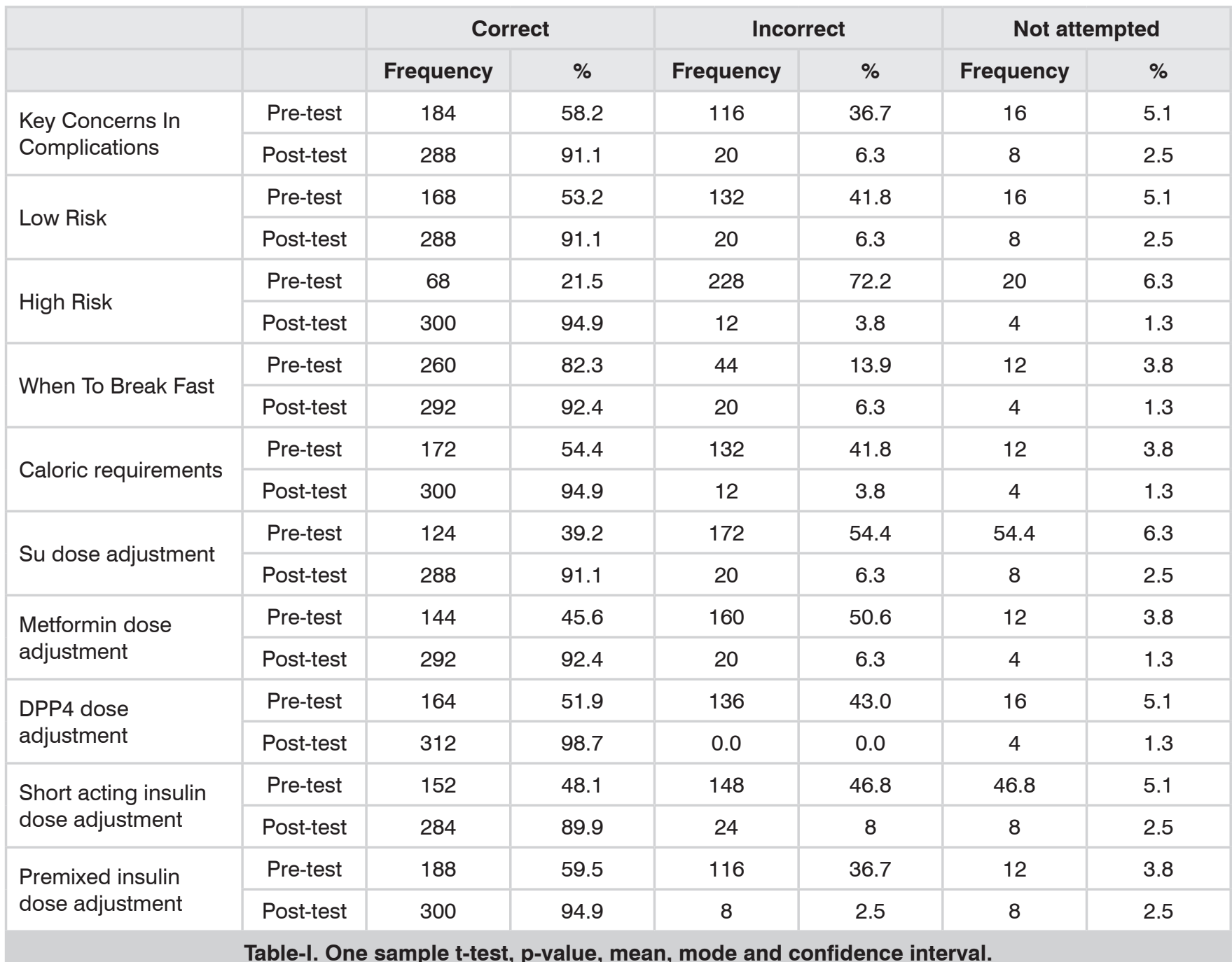




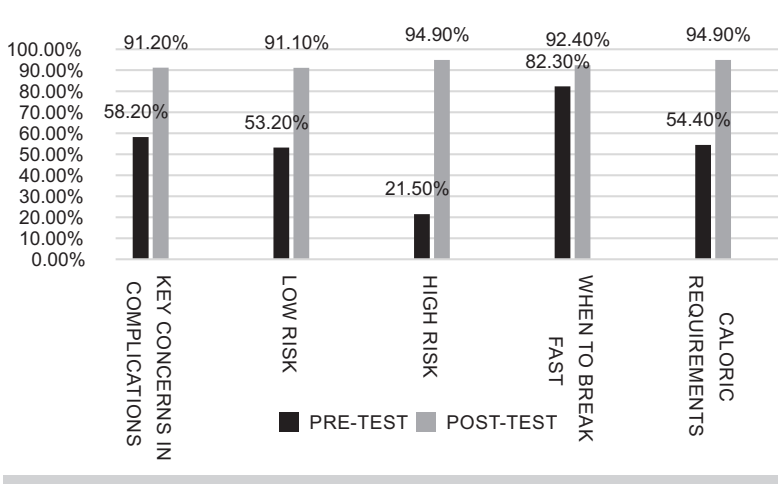

Figure-1.

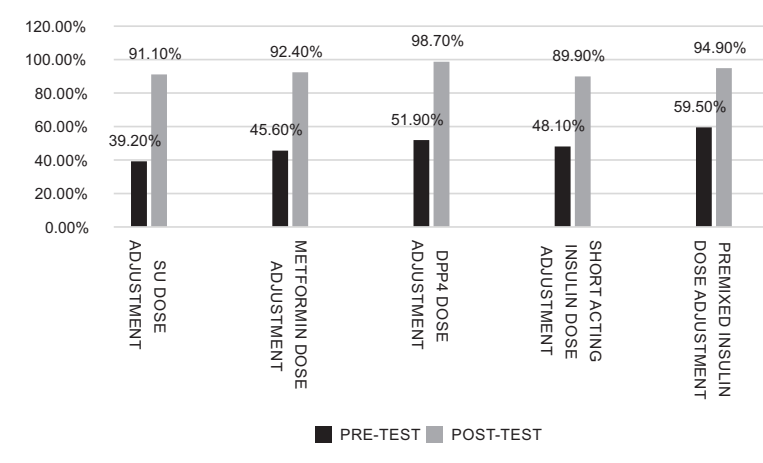

Figure-2.

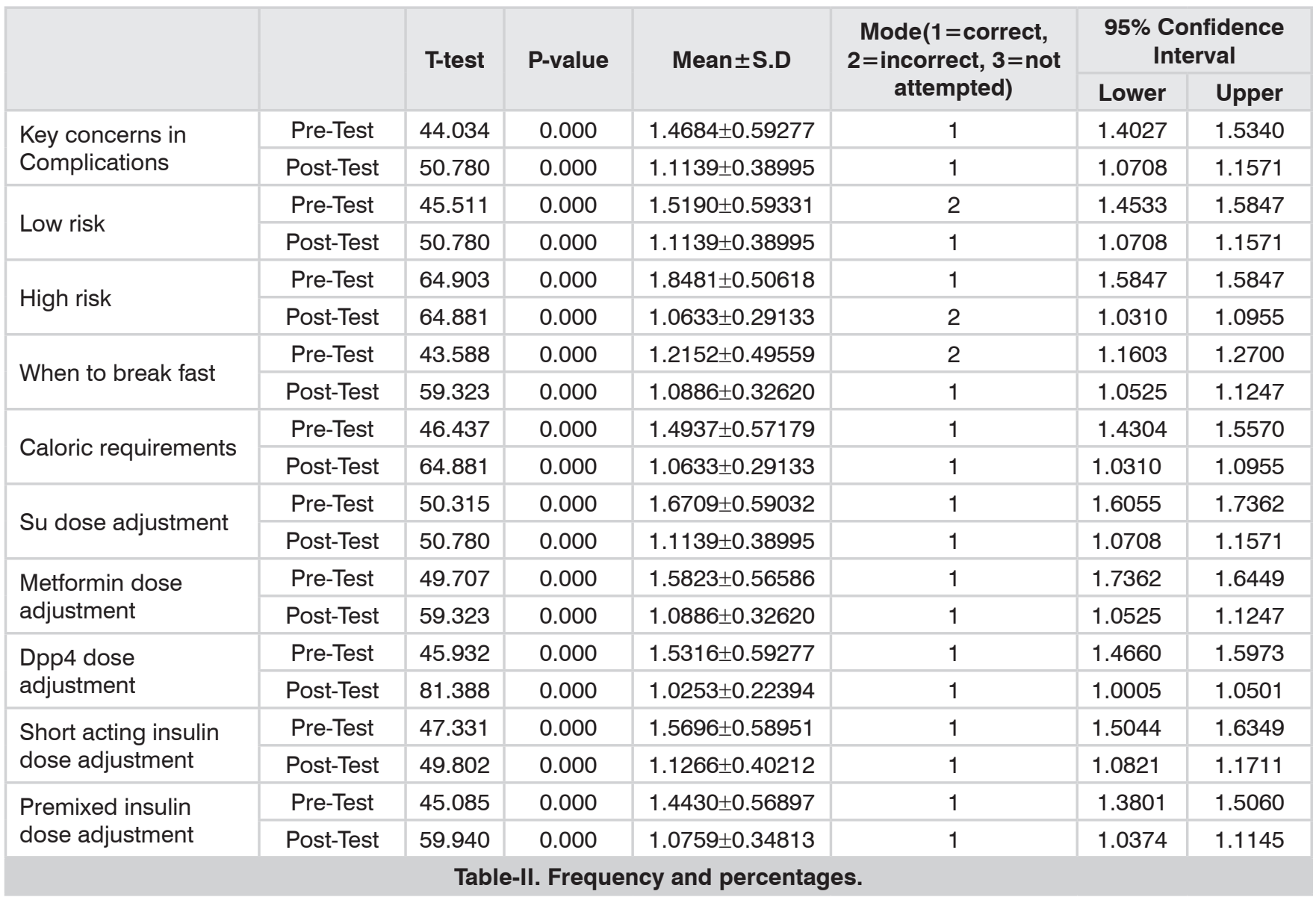

\section{DISCUSSION}

Assessment leads to better retention of knowledge. Assessment of learning is different from Assessment for learning, but used synonymously at times. Learning assessment can be formative as well as summative. It was considered that formative way was more receptive. However, we cannot right off summative learning process. ${ }^{6}$ The Guidelines were available for some time now. We were trying for few years to disseminate them. Hence pretest and posttest format was appropriate to assess the learning in the participants. ${ }^{7}$

Complications which can happen during Ramadan include Hypoglycemia, Hyperglycemia, Ketoacidosis, Dehydration and Thrombosis. Sueziani B. Zainudin et $\mathrm{al}^{8}$ have documented in a study that both hypoglycemia and hyperglycemia incidence reduced in Ramadan. A.V. Raveendran 
et $\mathrm{al}^{9}$ have published that fasting increased hypo and hyperglycemia, and it also increased the risk of ketoacidosis due to lack of diet control at iftar time with inappropriate medicine intake due to fear of hypoglycemia. Also dehydration and thrombosis could increase due to hot weather, sweating and osmotic diuretic effect of poor control of diabetes. In our study, we found that our healthcare professionals were predominantly aware of these issues. Their improvement was very significant after the completion of workshop, and crossed $91 \%$. Having a better understanding of complications was likely to improve safe fasting in diabetics.

Risk stratification was important aspect to know in Ramadan, before someone starts to fast. $\mathrm{M}$ et $\mathrm{al}^{4}$ have discussed this in guidelines of IDF, and put that as first point. They had divided patients in four risk groups, low, moderate, high and very high. According to them, low risk patients can fast without consultation with healthcare professional, moderate should consult and adjust medication, high should definitely make major adjustments in diet, exercise and medication with close monitoring. However, very high risk group should not fast. Jawad $\mathrm{F}$ et $\mathrm{al}^{10}$ suggested in editorial a holistic trial design in fasting diabetics, so that spiritual aspects could also be checked along with biochemical parameters of improvement. We found that our participants had poor knowledge about high risk stratification, but the workshop was very useful in improving it. Low risk group knowledge also improved significantly. However, we do not know if this was retained for a longer period. We therefore suggest studying it in future.

Diet, exercise and fluid intake were important information for fasting diabetics. Fernando et al ${ }^{11}$ documented in a meta-analysis that there was reduction in fat mass and weight in fasting. Almeneessier et $\mathrm{al}^{12}$ concluded that Diurnal intermittent fasting had effect on decreasing plasma cytokine levels, suggesting beneficial effects of fasting on people without Ramadan. Ismail $S$ et $\mathrm{al}^{13}$ documented that time restricted feeding and Islamic fasting have many similar effects and show positive benefits. The restriction of calories and water does not badly affect subjects. Our study checked the knowledge in participants on diet, exercise and fluid intake. Pretest knowledge was significantly improved after attending workshop. Although details were not asked in question on amount of fluid, diet or exercise during pre and posttest, but it was discussed extensively during the workshop, improving concepts and clearing confusions. Again, it was felt that retention should be rechecked after some time.

Knowledge about medicine adjustment in Ramadan was foremost important. Abolaban et $\mathrm{al}^{14}$ addressed all the issues from the perspective of primary care physicians. They emphasized that competence in cultural knowledge aspects were important for them, and clear guidelines were required. There were certain medication like metformin, DPP-4, thiazolidinedione, acarbose short acting secretagogues, GLP-1 RAs and SGLT2 inhibitors which were either requiring minimum or no adjustment in dosage. Newer Sulphonylurea drugs required definite dose adjustment with special care at dawn (sehar) time, whereas old sulphonylureas like Glibenclamide were not recommended. Same was the case with Insulin, as short acting and ultra-short acting insulins required minimum adjustment at sehar, with iftar dose staying same. Long acting and intermediate acting insulins also required adjustments. Pre-mixed insulins if given once, were continued at iftar, but twice daily required adjustment at sehar. In our study, we tested this knowledge. It appeared that in oral medicine, Sulphonylurea dose adjustment knowledge was most deficient, and so was short and long acting insulin dose adjustment. Improvement was remarkable at posttest, signifying the affectivity of knowledge delivery. However, this was something very obvious that we had no way to gauge it after sometime.

\section{CONCLUSION}

Interactive workshop based case discussion improved the retention of knowledge among participants, which in turn would benefit patients indirectly and promote safe fasting. More elaborative future research should be done with a control group to teach by conventional lecturing. It 
can help in devising a uniform policy for teaching.

\section{LIMITATIONS}

There were several limitations in this study. First, knowledge retention in only one group was assessed. It would have been better, if a control group of similar participants was included, which were given same information, using another tool like conventional lecturing. Second, although reading material was provided to the participants, but it was given at the start of workshop. Results might have been different if same material was given few days before workshop. Third, only doctors were involved in the study. The results could be different if patients were also included, but then, level of baseline qualifications would have created more challenge. Fourth, the participation was free will, and no force behind it. Workshops also took place in different cities, where patient experience could have been different. Finally, no religious clerk was involved as expert, which would have resulted in better outcome in understanding on relevant questions.

\section{ACKNOWLEDGEMENTS}

The authors would like to acknowledge the team of Medical Unit 2, mainly, Muhammad Maqsood, Usama Azhar, Faiz ur Rasool, Kashif Aziz Ahmad, Muhammad Suhaib, Maryam Islam and Ambreen Asif for helping in carrying out these Workshops in different cities of Punjab.

Copyright@ 12 Aug, 2020.

\section{REFERENCES}

1. Bener A, Al-Hamaq AOAA, Öztürk M, Çatan F, Haris $\mathrm{PI}$, Rajput $\mathrm{KU}$, et al. Effect of ramadan fasting on glycemic control and other essential variables in diabetic patients. Ann Afr Med. 2018; 17(4):196-202. DOI: 10.4103/aam.aam_63_17.

2. Badshah A, Haider I, Humayun M. Management of diabetes in Ramadan. J Ayub Med Coll Abbottabad. 2018 Nov 26; 30(4):592-598.

3. Guess ND. Dietary interventions for the prevention of type 2 diabetes in high-risk groups: Current state of evidence and future research needs. Nutrients [Internet]. 2018 Sep 6; 10(9). Available from: https:// www.ncbi.nlm.nih.gov/pmc/articles/PMC6163866/ DOI: 10.3390/nu10091245.
4. Hassanein M, Al-Arouj M, Hamdy O, Bebakar WMW, Jabbar A, Al-Madani A, et al. Diabetes and Ramadan: Practical guidelines. Diabetes Res Clin Pract. 2017 Apr; 126:303-316. DOI: 10.1016/j.diabres.2017.03.003.

5. Shah VS, Cavalcanti M, Scheetz S, Bahner DP, Dornbos DL, Prats MI. Teaching neurological disorders with ultrasound: A novel workshop for medical students. Brain Circ. 2020 Feb 18; 6(1):38-46. DOI: 10.4103/ bc.bc_30_19.

6. Peeters MJ. Targeting assessment for learning within pharmacy education. Am J Pharm Educ [Internet]. 2017 Oct; 81(8). Available from: https://www.ncbi.nlm. nih.gov/pmc/articles/PMC5701328/ DOI: 10.5688/ ajpe6243.

7. Shivaswamy KN, Shyamprasad AL, Sumathy TK, Ranganathan C, Kumar SP. Knowledge of acne among medical students: Pretest and Posttest Assessment. ISRN Dermatol [Internet]. 2014 Jan 28; 2014. Available from: https://www.ncbi.nlm.nih.gov/pmc/articles/ PMC3926269/ DOI: 10.1155/2014/727981.

8. Diabetes education and medication adjustment in Ramadan (DEAR) program prepares for selfmanagement during fasting with tele-health support from pre-Ramadan to post-Ramadan [Internet]. [cited $2020 \mathrm{Apr}$ 7]. Available from: https://www. ncbi.nlm.nih.gov/pmc/articles/PMC6116763/ DOI: $10.1177 / 2042018818781669$.

9. Diabetes control during Ramadan fasting | Cleveland Clinic Journal of Medicine [Internet]. [cited 2020 Apr 7]. Available from: https://www.ccjm.org/content/84/5/352. long DOI: https://doi.org/10.3949/ccjm.84a.16073

10. Ramadan and diabetes: Holistic Trial Design PubMed [Internet]. [cited 2020 Apr 8]. Available from: https://pubmed.ncbi.nlm.nih.gov/27427122/?from_ter$\mathrm{m}=$ risk + stratification + ramadan + in + diabetics \& from_filter=simsearch2.ffrft\&from_filter=ds1.y_5\&from_ pos $=4$.

11. Fernando HA, Zibellini J, Harris RA, Seimon RV, Sainsbury A. Effect of Ramadan fasting on weight and body composition in healthy non-athlete adults: A systematic review and meta-analysis. Nutrients [Internet]. 2019 Feb 24; 11(2). Available from: https:// www.ncbi.nlm.nih.gov/pmc/articles/PMC6412279/ DOI: 10.3390/nu11020478.

12. Almeneessier AS, BaHammam AA, Alzoghaibi $M$, Olaish AH, Nashwan SZ, BaHammam AS. The effects of diurnal intermittent fasting on proinflammatory cytokine levels while controlling for sleep/wake pattern, meal composition and energy expenditure. PLoS ONE [Internet]. 2019 Dec 10; 14(12). Available from: https://www.ncbi.nlm.nih.gov/pmc/articles/ PMC6903761/ DOI: 10.1371/journal.pone.0226034. 
13. SI,RaM,AM.Comparisonoftime-restrictedfeedingand Islamic fasting: A Scoping Review [Internet]. Eastern Mediterranean health journal $=$ La revue de sante de la Mediterranee orientale $=$ al-Majallah al-sihhiyah li-sharq al-mutawassit. 2019 [cited 2020 Apr 8]. Available from: https://pubmed.ncbi.nlm.nih.gov/31210344/?from te $r m=r a m a d a n+w a t e r+i n t a k e \& f r o m-$ filter=simsearch2.ffrft\&from_filter=ds1.y_5\&from_ pos $=6$ DOI: $10.26719 /$ emhj.19.011.
14. Abolaban $\mathrm{H}$, Al-Moujahed A. Muslim patients in Ramadan: A review for primary care physicians. Avicenna J Med. 2017; 7(3):81-87. DOI: 10.4103/ajm. AJM_76_17.

\begin{tabular}{|c|c|c|c|}
\hline \multicolumn{3}{|c}{ AUTHORSHIP AND CONTRIBUTION DECLARATION } \\
\hline Sr. \# & \multicolumn{1}{|c|}{ Author(s) Full Name } & \multicolumn{1}{c|}{ Contribution to the paper } \\
\hline 1 & M. Imran Hasan Khan & $\begin{array}{l}\text { Original idea, Review of literature } \\
\text { and the manuscript writing, Final } \\
\text { write up and approval, Final } \\
\text { review. } \\
\text { Data collection, Data analysis, } \\
\text { Final review. } \\
\text { Data collection, Literature review. }\end{array}$ \\
\hline 3 & Salman Shakeel & Rana Asif Sagheer & $\begin{array}{l}\text { Hafiz Ehsan Ullah } \\
\text { Data collection, Literature review. }\end{array}$ \\
\hline 5 & Usama Azhar & Statistical analysis, Final review.
\end{tabular}

